\title{
Übersetzungshotline des FVDZ gestartet
}

Der anhaltende Flüchtlingsstrom betrifft auch viele Zahnärzte in Deutschland. Wenn Asylbewerber aus dem arabischen Raum mit akuten Zahnschmerzen in die Praxen kommen, gibt es nicht selten ein Problem: Die Patienten sprechen oft weder Englisch noch Deutsch. Damit die Verständigung über Diagnose und Behandlung dennoch möglich ist, hat der Freie Verband Deutscher Zahnärzte (FVDZ) Mitte November einen Übersetzungsservice gestartet - exklusiv für FVDZ-Mitglieder.

Bei dem Pilotprojekt steht in Niedersachsen von Montag bis Freitag jeweils von neun bis $12.30 \mathrm{Uhr}$ die gebürtige Syrerin Wafaa Alhasan telefonisch zur Verfügung. Bevor sie schwanger mit ihrem Mann per Visum nach Deutschland kam, um dem Krieg in Syrien zu entfliehen, hatte sie in ihrem Heimatland als Zahnärztin gearbeitet. In Deutschland lernte die heute 35-Jährige zunächst die deutsche Sprache und absolvierte eine entsprechende Prüfung. Für den Übersetzungsdienst beherrscht sie Hocharabisch genauso wie den in Syrien üblichen Dialekt des Syrisch-Arabischen sowie das Kurdische. „Ich bin eine Kurdin, so dass das auch meine Muttersprache ist“, erzählt Alhasan. Von den zahlreichen Dialekten in Syrien kennt sie eigenen Angaben zufolge 99 Prozent. Somit kann sie auf eine breite Sprachpalette zurückgreifen.

\section{Keine eigene Diagnose oder Therapievorschläge}

Der Übersetzungsservice ist exklusiv und kostenlos für FVDZMitglieder. Es fallen nur die üblichen Telefonkosten aus dem
Festnetz und dem Mobilfunknetz an. Und so funktioniert es: Wenn sich Zahnarzt und Patient nicht ausreichend verständigen können, muss zunächst ein Formular unterschrieben werden, mit dem der Patient den Zahnarzt von seiner zahnärztlichen Schweigepflicht entbindet. Anschließend kann die Hotline unter Tel. 0228/8557-88 angerufen werden.

Dieses Formular gibt es sowohl auf Deutsch als auch auf Arabisch zum Download unter www.fvdz.de. Auf der Webseite ist ebenfalls ein Leitfaden zu finden, den der Freie Verband entwickelt hat, damit die Übersetzung rechtlich unbedenklich ist. Die syrische Zahnärztin darf ausschließlich Erläuterungen des Kollegen übersetzen, aber keine eigene Diagnose stellen oder Therapievorschläge machen.

Alhasan hat sich vorm Start des Politprojektes sehr auf ihre neue Aufgabe gefreut: „Ich bin gespannt auf die Arbeit und den Kontakt zu Patienten aus meiner Heimat.“

Melanie Fügner

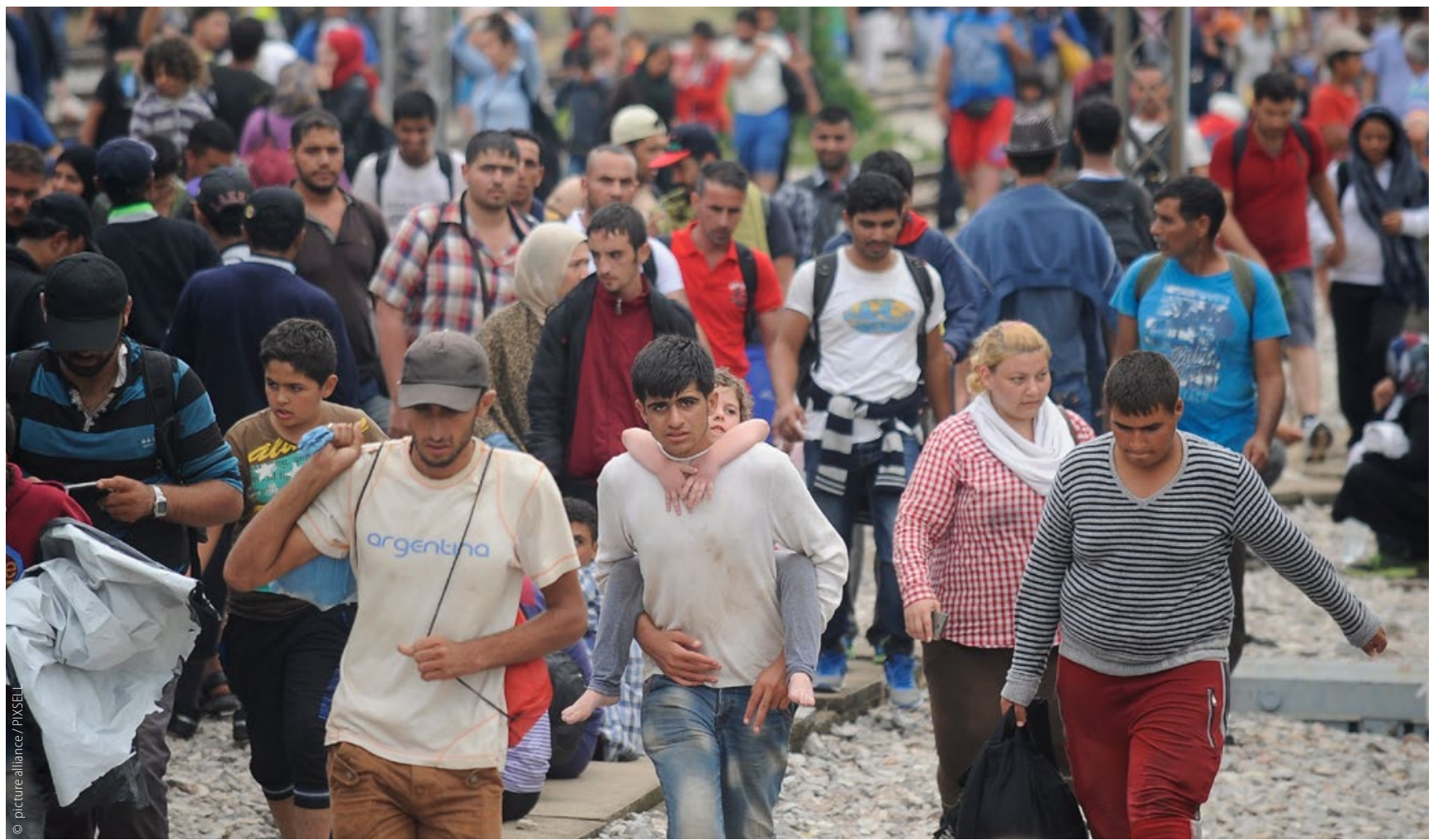

